\title{
Celebrating 20 Years of LINKS
}

We people like round figures and find in them an inspiration for celebration. Adding a zero to a number has something magic to it and is considered to signify a transition.

Actually the zero is rather new in the history of numbers. The word algebra originates from the Arabic word al-jabr, which literally means completion, and it was Muhammed Ibn Musa Al-Khwarizmi (s) (s) from Baghdad who exercised the chief influence on Medieval European algebra. Al-Khwarizmi, whose name is the root of our word algorithm, had not invented the zero himself. That honour belongs to an unknown Hindu, living several centuries earlier.

Before the introduction of the zero, calculating large numbers was complicated. In daily life there was also no real need for it. In Hindu many names like viya (sky), dambar (atmosphere), akasasa (space), sunya (void) and bindu (dot) were used to indicate zero. Where in Vedic tradition the zero was connected with 'nothing' the nothingness that contains, pervades and underlies everything - the Roman Catholic Church fulminated against what they considered to be the number of the devil. Zero, nothing, was equivalent to Satan. Nothing good could come from it. One could say that the zero brings the infinite within the realm and the consciousness of men.

The zero also plays an important role in homeopathy. Creating infinitesimal potencies, going beyond Avogadro's number, is moving from the one (the substance) to the zero (the immaterial equivalent of that substance), and it is no surprise that some see in homeopathy therefore also the work of the devil, or at least a trespass into the realm of God. The zero completes the one, darkness completes light, female completes male, disease completes health, homeopathy completes allopathy.

This year LINKS celebrates its twentieth anniversary. Into the pages of this cutting-edge journal, several new developments have entered: developments that have being considered by some as having zero substance, a serious threat to homeopathy, or a least a trespass beyond Hahnemannian territory.

This year and in those to come, the further completion of homeopathy will be a main topic. Homeopathy, by some considered as a complete never-changing Hahnemannian 'one', will develop further by integrating and adding an infinitesimal number of new 'zeros'. The completion of homeopathy will never end. It is not a matter of whether it should or will happen, but rather one of how to guide and feed this process in the best possible way.

LINKS has now left its teens, has moved through adolescence, and may be expected to show signs of adulthood. Looking back at the turbulent developments that have enlivened its pages and moving forwards with a process of consolidation is part of this new phase. Homeopathy needs to touch base, its philosophy needs to encompass past and present and to be prepared for the future, new developments that stand the test of practice need to be connected to and integrated with its foundation.

The zero is now to complete the two, the two being Hahnemann's foundation of classical homeopathy and new approaches built on it. The two is also homeopathy and its ally allopathy for neither is complete without the other.

In this year 2007 the LINKS team intends to celebrate the completion of one phase and the start of a new one. We hope to do this together with you, our readers, on the very pages of the journal as well as at the Celebrating LINKS Conference in Heidelberg next October.

I think we can all say 'Happy Anniversary' to each other!

Harry van der Zee, Editor 